\title{
Cotidiano
}

Alexandre Freitas Marchiori'

Ana Gláucia do Carmo Silva²

\section{Currículos compartilhados em um CMEl da rede municipal de Vitória: educação física, arte, música e alfabetização}

Neste relato intentamos compartilhar as experiências e práticas desenvolvidas no Centro Municipal de Educação Infantil (CMEI) Dr. Denizart Santos no ano de 20 I3, particularmente, analisamos os projetos da sala do Grupo VI (crianças de 05 anos): "Vitória, entre praias e montanhas" e o projeto "Musicalização na Educação Infantil (EI)", em diálogo com dois relatórios produzidos pelos professores de Educação Física e Artes. Objetiva-se analisar essa atuação compartilhada entre os diferentes profissionais, com formação em Pedagogia e Educação Física e como esse currículo da El pode ser dinâmico e envolver as crianças, reconhecendo-as como protagonistas das ações no CMEl. A coletividade, expressa nas práticas analisadas neste trabalho, permite evidenciar as especificidades desse espaço educativo. Os interesses dos sujeitos caminham no sentido do atendimento das necessidades das crianças que incluem os aspectos do cuidar e educar.

Palavras-chave: Educação infantil; Currículo. Alfabetização.

\section{Shared curriculum in the CMEl of Vitória: physical education, art, music and literacy}

In this report we aimed share experiences and practices developed in the Municipal Center for Early Education (MCEE) Denizart Dr. Santos in 2013, particularly, we analyzed the projects of Group VI (children of 05 years old) class: "Vitória, between beaches and mountains" and the project "Musicalization in Early Childhood Education (ECE) ", in dialogue with two reports produced by teachers of Physical Education and Arts. The objective is to analyze this shared activity between the different professionals with training in Pedagogy and Physical Education curriculum and how that ECE can be dynamic and involve children, recognizing them as active protagonists in MCEE. The community expressed in the practices analyzed in this work, allows us to highlight the specificities of this educational area. The interests of the subjects go towards meeting the needs of children that include aspects of to care and to educate.

Keywords: Children Education. Curriculum. Literacy.

I Mestre em Educação pelo PPGE/UFES. Professor da Educação Básica - Educação Infantil da PMV; Professor da Faculdade Pitágoras/Guarapari-ES. Email: alexandremarchiori@yahoo.com

2 Graduada em Pedagogia. Professora da Educação Básica -PMV. Prefeitura Municipal de Vitória. E-mail: a.glaucia.silva@bol.com.br 


\begin{abstract}
Quero destacar uma ideia de currículo que enfatiza seu aspecto produtivo e interativo. Isto é, o currículo não está constituído por informações, conceitos, princípios que são passados para os/as alunos/as (geralmente organizados sob a forma de lista de "conteúdos" - aquilo que deve ser ensinado). O currículo é o que crianças e professoras/es produzem ao trabalhar com os mais variados materiais. [...] não é o conhecimento preexistente que constitui o currículo, mas o conhecimento que é produzido na interação educacional (CRAIDY; KAERCHER, 200 I, p. I8-19).
\end{abstract}

Introdução

atuação e a forma que temos encontrado para vivenciarmos a Educação Infantil (EI)
dialogam incisivamente com a experiência de constituição docente pela qual todos os professores passam. Reconhecemos as transitoriedades dos saberes e conhecimentos que só ganham sentidos na companhia do outro, quer seja este outro um adulto ou as crianças. É interessante observar essa complexa rede tecida com as crianças e perceber que o conhecimento, ao mesmo tempo em que ganha sentido é rapidamente ressignificado, especialmente quando trabalhamos com culturas infantis. Um bom exemplo disso são as músicas infantis: até os 03 anos é fácil e tranquilo cantarmos "Pintinho Amarelinho, Borboletinha, A Barata, O Elefante, O Sapo" e tantas outras desse universo que reconhecemos como pertencentes às culturas da infância ${ }^{3}$, porém, causa espanto quando ouvimos de crianças de 04 anos reclamar e dizer: - Eì? Música de criança "tio "? Coloca outra música "tio"!

Diante dessas particularidades e especificidades da EI, colocamo-nos a refletir sobre o trabalho docente e o que oferecer às crianças, quais conteúdos podem ser abordados em diálogo com o Projeto Institucional e as diretrizes da EI? Quando decidimos coletivamente sobre um tema a ser abordado, os diferentes sujeitos são convidados a produzir um currículo e planejar suas intervenções

\footnotetext{
3 Entendemos infância como esse espaço habitado/vivido pelos sujeitos crianças e pode ser considerado plural, pois serão tantas infâncias quanto à diversidade de crianças e seus contextos que podemos produzir ou construirmos.

4 Essa forma de tratamento é aceita com naturalidade pelos educadores, entretanto, o modelo escolar também está presente ao indicarmos e ouvirmos os professores dizendo às crianças: - hoje, vocês terão aula de "Educação Física, Artes, Informática, Música" com o professor; ou alertando às crianças: - não é tio(a), é professor! Esta fala, ao mesmo tempo, pode indicar o reconhecimento da função docente e a necessidade de ensinar às crianças a figura desse adulto na formação que recebem no CMEl.

5 Normalmente, as preferências das crianças são as músicas que estão nas paradas de sucesso, tocam em rádios e/ou são temas de novelas. Expressam essa cultura que têm acesso em suas famílias. O funk é reconhecido facilmente como preferência das crianças, seguidos das músicas evangélicas infantis (Aline Barros, Cristina Mel, Diante do Trono e outros).
} 
em diálogo com a rotina dessa instituição. Cremos ser este um importante marco para pensarmos as experiências e vivências nas instituições infantis: as especificidades das áreas de conhecimentos se encontram para produzir e reconhecer as especificidades da Educação Infantil, seus saberes e sua volatilidade. Para além, acreditamos na potência dos encontros produzidos com e pelas crianças, sujeitos da ação - como propõe Piaget, sujeitos epistêmicos ${ }^{6}$ - que se apropriam das culturas e produzem novos sentidos a partir dessas afecções.

Neste sentido, reconhecemos a importância de cada sujeito da educação infantil, com seus saberes e história de vida. Ao escrevermos este texto não conseguimos nos desvencilhar das marcas deixadas em nós, professores da educação infantil, por cada criança que já passou pelas instituições infantis na qual trabalhamos; pelas experiências docentes que foram dialogadas e formaram a coletividade do CMEI DS. Sempre estamos aprendendo com o outro, incluindo aqui nossas crianças, estas que mobilizam saberes e fazeres dinâmicos.

A constituição docente é alimentada por essas relações interpessoais, pela tensão entre as relações de poder e, também, pelos desejos das crianças. A pressão da cultura midiática compõe esse universo educacional/formativo, empurra-nos para o consumo de bens culturais, instiga-nos a acompanhar as mudanças dos "sucessos do momento", da cultura novelística em tensão contínua com as culturas infantis consolidadas ao longo da história humana. Ficamos divididos entre o que é importante para a formação dos sujeitos e as "necessidades escolares" das crianças. Há sempre uma escolha curricular nas instituições infantis. Se pensarmos/planejarmos coletivamente, acreditamos que será possível irmos de encontro aos desejos das crianças, permitindo que esse tempo da Educação Infantil seja único.

Para este trabalho, intentamos compartilhar as experiências e práticas desenvolvidas no CMEI Denizart Santos no ano de 2013, particularmente, analisaremos os projetos da sala do Grupo VI (crianças de 05 anos): "Vitória, entre praias e montanhas" e o projeto "Musicalização da EI", em diálogo com dois relatórios produzidos pelos professores de Educação Física e Artes .

Objetiva-se analisar essa atuação compartilhada entre os diferentes profissionais, com formação em Pedagogia e Educação Física e como esse currículo da EI pode ser dinâmico e envolver as crianças, reconhecendo-as como protagonistas das ações nos CMEIs.

A título de organização, apresentaremos um esboço dos projetos apresentados pelos

\footnotetext{
6 Também chamado de sujeito cognoscente ou do conhecimento, o conceito diz respeito às estruturas mentais comuns a todos os seres humanos, que conferem a possibilidade de aprender fazendo relações entre diferentes informações (classificação, comparação, dedução etc.). Tais estruturas se desenvolvem do início ao fim da vida por meio da ação dos individuos sobre o meio, num processo de interação com o objeto de conhecimento e com as outras pessoas, o que possibilita a construção de níveis de saber cada vez mais complexos (Piaget). Fonte: Ver. Nova Escola, p. 65, dez. 2010.

7 Atualmente, são dois professores de Educação Física atuando nesse CMEI. A professora Giovana ficou afastada até 30/I 0 devido Licença de Mestrado, ficando em seu lugar uma professora regente de sala, com extensão de carga horária.

8 A professora titular de Artes está afastada para tratamento de saúde - licença médica. Em seu lugar atuaram 02 professoras regentes, com extensão de carga horária.
} 
professores, seguido dos relatórios apresentados ao final do primeiro e segundo semestres9. Seguiremos com algumas reflexões dessas experiências docentes e apresentaremos algumas considerações ou provocações que essa rede de saberes possibilita.

Projeto de Sala do Grupo VI "Vitória, entre praias e montanhas"

O projeto trazia um alerta logo no início do texto: "A praia é um bom local para nosso lazer, mas é preciso tomar cuidados para não pôr nossas vidas em risco" (fonte não informada). Como objetivo geral sinaliza a perspectiva que as crianças conheçam as diferenças climáticas e culturais entre Vitória, com suas praias, e as montanhas Capixabas ${ }^{10}$.

A título de desenvolvimento, a professora sinalizou que iria trabalhar com histórias, aulas extraclasses como: Visita à Escola de Ciência Biologia e História, Peixaria no mercado da Vila Rubim, galpão das paneleiras em Goiabeiras, tour pelas praias de Vitória, finalizando com um piquenique no final da Praia de Camburi na última barraca do calçadão. Estava previsto também conhecer o Município de Domingos Martins e a Expomar Aquário de Guarapari ${ }^{11}$, onde passariam o dia. Como recursos e metodologias, destacou-se trabalhar com recortes de jornais e revistas, escritas e fichas de leituras, nome das praias, clima, vegetação, profissão, músicas, listar nome das praias, animais marinhos, artes dobraduras, entrevista às famílias (Quais produtos da pesca e agricultura estão presentes na alimentação diária?) e confecção de murais. Além de abordar os cuidados que devemos tomar ao ir à praia, seriam utilizados mapas e globo para visualizar áreas do mar (oceano) e montanhas (área verde), fazer uso do episcópio com imagens dos livros.

A professora, em diálogo com a pedagoga, destacou, ainda, alguns pontos turísticos e assuntos tangenciais: Pedra Azul, Domingos Martins: turismo ecológico, agro turismo, colonização europeia, principalmente alemã e italiana.

Referente ao letramento e alfabetização, por entender que esse grupo de crianças está se despedindo da educação infantil e iniciará o primeiro ano no ensino fundamental, objetivou-se um trabalho mais sistemático. Neste sentido, o projeto teve por objetivo geral conhecer e reconhecer as letras do alfabeto, identificar números, quantidades e cores. As ações caminharam para que esse tempo na EI possibilitasse às crianças experimentarem: conhecer as letras através de pequenos

\footnotetext{
9 A professora Regente de sala fez um relatório individual, no qual constava os trabalhos de sala, as intervenções e a avaliação das crianças, contudo, não foi objeto de análise neste trabalho. Os relatórios a que nos referimos foram produzidos para compor a avaliação das turmas.

10 Segundo os estudiosos da língua tupi, capixaba significa, roça, roçado, terra limpa para plantação. Os índios que aqui viviam chamavam de capixaba sua plantação de milho e mandioca. Com isso, a população de Vitória passou a chamar de capixabas os índios que habitavam na região e depois o nome passou a denominar todos os moradores do Espírito Santo. Fonte: Site oficial do Estado do ES: http://umw.es.gov.br/EspiritoSanto/paginas/origem_do_termo_capixaba.aspx.

II Aquário com uma grande biodiversidade marinha, conta com tubarões, mais de 100 espécies vivas, minimanguezal, com sistemas de mares e aquários de água doce com piranhas do pantanal, traíras e tucunarés. Realizam também venda de souvenir e turismo pedagógico. Fonte: http://mww.guarapari.es.gov.br/v3/index.php/nautico/expomaraquario-de-guarapari.html.
} 
textos, listas de palavras do mesmo campo semântico, alfabeto móvel, jogos didáticos, adivinhas, receitas, recortes e colagens, pintura, ilustração, músicas, quantidade de letras na palavra, atividades espontâneas, tarefa de casa, seleção de livros (projeto ciranda de livros), correção da tarefa de casa.

Nesse projeto, ainda constava o indicativo de desenvolver o projeto musicalização. $\mathrm{O}$ objetivo desse trabalho era "desenvolver nas crianças o amor pela música e prepará-las, com alegria, para a prática vocal e instrumental". Pontuaram-se dentre as ações planejadas: trabalho com o corpo; explorar os instrumentos e seus respectivos nomes trabalhando com a escrita em sala; selecionar artistas e cantores para explorar suas músicas; e, trabalhar a letra da música em sala, construção coreográfica e apresentação cultural.

Para além, o grupo também contemplou em sua rotina temas e conteúdos sugeridos pela empresa TECHINIP ${ }^{12}$ e outros que surgiram no decorrer do processo.

\section{Projeto Musicalização no CMEI Dr Denizart Santos}

O projeto iniciava com o alerta sobre a proposta de intervenção com música e o reconhecimento de uma lacuna formativa desses professores. A estrutura e a forma argumentativa tentavam justificar a inserção desse profissional, formado em Educação Física, atuando na área de Música. Havia uma incerteza se essa experiência seria frutífera, pois a formação na área ou a ausência desse especialista em Música poderia inviabilizar a intenção desses sujeitos. Cabe destacar que houve um convite, pois ambos os docentes envolvidos desejavam esse trabalho, mas, ao escolher atuar com esse conteúdo, foi necessário abrir mão de atividades e outras possibilidades de utilizar esse tempo com as crianças.

O tema "Por dentro do Espírito Santo" foi escolhido para o Projeto Político Pedagógico do CMEI, buscando orientar as práticas educativas a serem desenvolvidas no ano de 2013. A proposta deste projeto era buscar uma aproximação com a produção artístico-cultural do povo capixaba, todavia, entendemos que a música alcança dimensões que ultrapassam fronteiras culturais e já não é possível regionalizar a cultura brasileira. Somos um povo, com uma diversidade cultural e o acesso a esse conhecimento necessita ser garantido às crianças da educação infantil.

Esse desejo de trabalhar a música no CMEI Denizart Santos surgiu da experiência que vivenciamos no final de 2012: quando propusemos uma apresentação musical com as crianças do Grupo VI e pedimos que escolhessem algumas músicas para apresentarmos aos demais grupos, percebemos a "limitação" nas escolhas das músicas, sendo apresentadas apenas os "rits do

12 Empresa que atua no Porto de Vitória e desenvolve parcerias com as escolas próximas. O CMEl é atendido, juntamente com duas Escolas Municipais de Ensino Fundamental no bairro. 
momento". Diante dessa demanda, percebemos a importância de sistematizar um trabalho com esse conteúdo, mesmo não existindo formação específica com música.

Esse movimento exigia um acompanhamento de um profissional formado em música para orientar o fazer docente e evitar equívocos conceituais. Mesmo acessando os referenciais da educação infantil e outros materiais teóricos, sentimos a necessidade de dialogar com a Secretaria de Educação e solicitar esse profissional.

Os professores entenderam ser importante destacar a perspectiva curricular que estavam adotando nesse projeto:

Importa que todos os conteúdos sejam trabalhados em situações expressivas e significativas para as crianças, tendo-se o cuidado fundamental de não tomá-los como fins em si mesmos. [...] Deve-se promover o crescimento e a transformação do trabalho a partir do que as crianças podem realizar com os instrumentos. Numa atividade de imitação, por exemplo, ao perceber que o grupo ou uma criança não responde com precisão a um ritmo realizado pelo professor, este deve guiar-se pela observação das crianças em vez de repetir e insistir exaustivamente sua proposta inicial (BRASIL, | 998, p. 6I).

$\bigcirc$ gesto e o movimento corporal estão intimamente ligados e conectados ao trabalho musical. A realização musical implica tanto em gesto como em movimento, porque o som é, também, gesto e movimento vibratório, e o corpo traduz em movimento os diferentes sons que percebe. Os movimentos de flexão, balanceio, torção, estiramento etc., e os de locomoção como andar, saltar, correr, saltitar, galopar etc., estabelecem relações diretas com os diferentes gestos sonoros (BRASIL, | 998, p. 6I).

Eis nosso desafio: uma prática significativa para a criança, interligada à área de Educação Física e o trabalho de sala.

Os objetivos corresponderam em desenvolver nas crianças o amor pela música e prepará-las, com alegria, para a prática vocal e instrumental; em consonância com o RCNEI (Brasil, 1998), explorar e identificar elementos da música para se expressar, interagir com os outros e ampliar seu conhecimento do mundo; e perceber e expressar sensações, sentimentos e pensamentos, por meio de improvisações, composições e interpretações musicais; desenvolver atividades lúdicas que permitiram a apropriação dos fundamentos básicos da música: Som, ruído e silêncio; Intensidade forte e fraco; Duração - curto e longo; altura - auto "grossos" e baixo "finos"; Timbre.

As ações planejadas caminharam no intuito de que as crianças conhecessem os instrumentos musicais, pudessem manuseá-los e aprendessem a tocar instrumentos de percussão, acompanhassem músicas utilizando o corpo e, também, os instrumentos. Almejava-se trabalhar conteúdos em sala de aula, abordando história de alguns cantores, encenar peça musical, apresentar composição musical e explorar o letramento e alfabetização a partir das letras das músicas, dos nomes dos instrumentos e 
elementos da música; conhecer diferentes culturas e gêneros musicais, estilos, ouvir e praticar essas diferentes formas de expressão: frevo, reggae, rock, forró, axé, pagode, samba, bossa nova, MPB, gospel, funk, hip hop, eletrônica, clássica.

O desenvolvimento das aulas foi planejado da seguinte forma: As aulas aconteceriam em fases distintas: $1^{\circ}$ - Trabalho com o corpo, com brincadeiras e os fundamentos da música; $2^{\circ}-$ Apresentar os instrumentos e permitir que se apropriassem das especificidades, explorando cada um deles, fazendo rodízio entre eles e acompanhando músicas infantis do conhecimento das crianças; $3^{\circ}$ - Explorar os nomes dos instrumentos na sala de aula, sua grafia, características e elementos da música; $4^{\circ}$ - Selecionar artistas e cantores para explorar as músicas, desenvolver o acompanhamento com percussão, interpretação e criação pelas crianças; $5^{\circ}$ - Trabalhar a letra da música em sala de aula, construção coreográfica e apresentação cultural; $6^{\circ}$ - Apresentações externas ao CMEI, interação com as escolas vizinhas, outros CMEIs.

A metodologia consistiu no trabalho com as crianças do GRUPO VI na "sala de movimento", dividindo a turma em dois grupos, com 30 minutos de intervenção para cada. A professora acompanhava o professor do "projeto música", enquanto a outra metade da turma desenvolvia o trabalho na sala de informática (Isso ocorreu no turno matutino). O turno vespertino seria contemplado em dois momentos distintos, devido à necessidade da divisão da turma, não sendo possível a integração com o horário de informática. As aulas da manhã aconteceram das 09h20minh às $10 \mathrm{~h} 20 \mathrm{minh}$, todas as quintas feiras. Pela tarde, estavam previstas aulas às terças e quintas feiras, das $15 \mathrm{~h} 20 \mathrm{minh}$ às $15 \mathrm{~h} 50 \mathrm{minh}$.

Os materiais didáticos disponíveis na escola para iniciar o trabalho eram Cds e DVDs, rádio, caixa de som, microfone, data show, televisão e alguns instrumentos musicais: 04 pandeiros; 02 triângulos; 01 Rebolo (Tantam); 06 Chocalhos; 02 tamborins; 01 meia lua; 02 agogôs; 01 violão adulto de propriedade do professor. As músicas escolhidas contemplavam os trabalhos de Tom Jobim, Adriana Calcanhotto (Adriana Partimpim 1, 2 e 3), Palavra Cantada, Marisa Monte, Música Clássica, Coleção de músicas infantis; Trilha sonora da Novela Carrossel. Os instrumentos musicais foram adquiridos no final do ano de 2012 e possuíam tamanhos e pesos padrão. Optamos em não trabalhar com materiais infantis por considerar a baixa qualidade do som e a fragilidade do material. Entretanto, tínhamos que administrar como as crianças poderiam utilizar os instrumentos, adequando-os ou deixando que elas encontrassem a forma mais confortável para tocar. 
Relatório do ${ }^{\circ}$ semestre: aprendizagens e significações, o trabalho de musicalização com crianças de 05 anos

O trabalho com musicalização só foi possível mediante a aquisição de instrumentos musicais e a parceria firmada entre os professores regente e de educação física. Antes do início desse trabalho, as práticas ocorriam separadamente. Cada professor desenvolvia sua prática docente e, quando possível, ocorriam aproximações pontuais ao longo do ano letivo. Os planejamentos vinculados ao movimento de entrada do professor de educação física/arte/música e saída da professora regente dificultam um trabalho dialogado, especialmente por considerar as especificidades de cada espaço e área de conhecimento. Propor um trabalho integrado significou oferecer a oportunidade de qualificar o tempo de atendimento das crianças na educação infantil. O projeto de musicalização exigiu adequações dos tempos e espaços da instituição, além de uma articulação pedagógica e apoio logístico oferecido pela pedagoga e direção da instituição.

A experiência do CMEI DS começou efetivamente no dia 07 de março de 2013. As primeiras aulas foram planejadas a partir do trabalho da "Palavra Cantada" ${ }^{13}$ ". No dia 07/03 planejamos quatro atividades:

1- Sentar e ouvir uma música instrumental - faixa 04/Palavra Cantada

2- Batucar a melodia - faixa 02/Palavra Cantada

3- Trabalhar o conceito de "ritmo" - faixa 02 (Yapo)

4- Acompanhar com palmas, usar o pandeiro (apresentar o instrumento) - faixa 12/Bebossa Kids.

Nessa aula, conseguimos trabalhar os sons com a boca "a, e, i, o, u"; tocar a orelha do colega e comentar sobre a audição; apresentar as "mãos" como nosso primeiro instrumento; abordar o conceito de "barulho" e "silêncio".

Na segunda aula (14/03) objetivamos trabalhar os sons do corpo, brincar com os sons. Como atividades, planejamos 06 momentos:

1-Sentar e ouvir uma música clássica - faixa 04/Joias da Música-Tchaickovsky

2- Apresentar os instrumentos e falar sobre os sons: de bater, de usar as mãos, chocalhar, balançar, uso da baqueta

3-Trava-língua - faixa 05 (Noé) - Palavra Cantada

4- Movimentar-se conforme a intensidade da música

5- Usar os chocalhos, coco e clave, acompanhar o ritmo e ouvir a música - faixa 07 (Ti cutuca)

13 Brincadeiras Musicais da Palavra Cantada é um projeto de ensino de música para crianças, elaborado com base na parceria da Editora Melhoramentos com o grupo Palavra Cantada, que visa contribuir para a construção de um trabalho de educação musical a ser realizado nas escolas. Fonte: http://projetopalavracantada.com.brl. 


\section{- Palavra Cantada}

6- Acompanhar a música “O que é o que é?” Gonzaguinha (viver e não ter a vergonha de ser feliz...) utilizando-se os tambores, pandeiros e tamborim.

Essa segunda aula teve uma característica interessante, pois o primeiro grupo veio acompanhado da professora Ana Gláucia. O segundo grupo compareceu sozinho e isso dificultou o trabalho, tendo em vista ter que chamar a atenção das crianças a todo instante e lembrá-los que aquela aula era de música e precisavam estar atentos ao andamento da aula.

A terceira aula (21/03) seguiu o seguinte planejamento:

1- Ouvir uma música com saxofone - faixa 08/Kenny G (Morning)

2- Trabalhar com o tamborim - ouvir música de samba e pagode - faixa 06/Palavra Cantada (Ciranda)

3- Repetir a música "Yapo" - faixa 02/Palavra Cantada (a pedido das crianças)

4- Percussão com colheres/agogô/trave - faixa 03/Palavra Cantada (Sopa de neném)

5- Trabalhar a faixa 09/Palavra Cantada - Vai e vem, com copo, fita ou barbante

Neste dia não trabalhamos com as colheres, tampouco a atividade 5. A música "O que é que tem na sopa do neném" permitiu explorar a produção de sons a partir do corpo, uso das mãos, pés, rosto, boca.

A quarta aula teve como objetivo oferecer acesso a diferentes gêneros musicais e trabalhar o "ritmo". Utilizamos o cd "Melodiário". Como primeira atividade, solicitamos que deitassem e ouvissem uma "Ópera" - faixa 04. A proposta foi oportunizar que explorassem os diferentes gêneros musicais e pudessem dançar/movimentar conforme a música oferecida.

1- Gêneros: Axé, MPB, Salsa, Gospel, Sertanejo

2- Cd Chiclete com Banana - faixa 08 e 16

3- Cd Salsa - faixa 1 e 5 (espanhol)

4-Cd Choro Novo - faixa 1 e 7

As crianças acharam "estranho" a ópera e fizeram comentários bem interessantes: "parece um lobo", "parece uma mulher louca". A proposta de movimento foi bem aceita e as crianças se divertiram. Neste dia a turma ficou junta, pois não houve aula de informática. A salsa foi uma grande brincadeira. Ao final foi solicitado que colocasse funk, mas isso ficou para a próxima aula. Como não conseguimos oferecer outros gêneros nessa experiência, ficamos de trabalhar o Gospel, o Rock e o Funk em outra aula.

Aos moldes da aula anterior, planejamos trabalhar os gêneros musicais (11/04). Para abertura da aula, oferecemos uma música alegre "Fico assim sem você" para que as crianças apenas escutassem. Como eles já conheciam, ficaram cantando enquanto estavam deitados. Solicitamos que 
sentassem e acompanhassem a música com a voz. Preparei um "pendrive" com 11 músicas e fomos oportunizando a exploração das crianças.

1- Deus da minha vida - Thalles Roberto

2- Funk-Vodka com água de coco

3-Funk-Dança sensual

4-Funk-elloHHHelloy Kit

5- Tema do filme Missão Impossível

Essa aula foi esperada com muita empolgação. As crianças ficaram perguntando se teria funk mesmo e se eles dançariam na quinta-feira. Quando colocamos o funk foi uma euforia só. Todas as crianças começaram a cantar em coro e dançavam alegremente. Foram três músicas intensas, coreografadas, vividas com alegria. Foi uma excelente aula, vivida na sua plenitude. Para nós ficou uma dúvida: como essa cultura fala tão forte às crianças! Diante disso, como trabalhar com essa cultura? O que fazer para levar as crianças a outros conteúdos culturais?

A sexta aula (18/04) decidimos trabalhar com os instrumentos musicais. Considerando que as crianças deveriam experimentar os instrumentos e tocá-los, organizamos o palco (pátio) para que as crianças vivenciassem esse momento. Disponibilizamos o material no palco e permitimos que escolhessem os instrumentos. Escolhemos cinco músicas infantis para facilitar o acompanhamento e o trabalho pedagógico em sala de aula. Inicialmente, elas deveriam bater palmas e cantar, posteriormente, acompanhar com os instrumentos. As músicas foram: Caranguejo não é peixe; Marinheiro só; Perdi meu anel no mar; Peixe vivo; e Se eu fosse um peixinho.

Essa aula foi repetida até que conseguíssemos a apropriação dos elementos musicais e preparássemos uma apresentação cultural como fechamento desse primeiro momento do projeto. Avaliamos que era possível trabalhar com o violão e fazer as trocas dos instrumentos ao longo dos ensaios. O tambor sempre era o instrumento mais desejado pelas crianças e tentávamos oferecer o acesso e o manuseio de todos os instrumentos. Ao longo das aulas discutíamos sobre o modo de tocar, a melodia, o acompanhamento, a intensidade do som, propriedades do som. $\mathrm{O}$ trabalho em sala de aula contemplou explorar os nomes dos instrumentos, as letras das músicas e as experiências sonoras.

A apresentação ocorreu no dia 08/05. As crianças deram um show de ritmo e a plateia interagiu ao longo de todo o trabalho. Avaliamos que o trabalho com música pode ser oferecido às crianças quando há planejamento sistemático, envolvimento e dedicação de todos (crianças e adultos). Alcançamos o objetivo de possibilitar a apropriação dos elementos da música e o acesso a instrumentos de percussão verdadeiros (leia-se: oficiais, com qualidade de som e durabilidade).

A participação da professora Ana Gláucia e seu envolvimento com o projeto permitiu o 
aprofundamento necessário. Com isso, as crianças respeitaram os momentos na "sala de movimento", aceitaram o convite para se trabalhar com a música.

A música, a dança e, consequentemente, a Educação Física estiveram presentes na formação desses sujeitos sociais e históricos. Alguns pais compareceram à escola, a convite das crianças e professora, e prestigiaram a apresentação.

O relatório se encerrava neste ponto e não chegamos a fazer o segundo relatório do projeto. Contudo, acreditamos ser importante compartilhar a sequência dos trabalhos e as particularidades que enfrentamos nesse planejamento.

Na sequência do projeto, decidimos abordar a capoeira e seus elementos rítmicos, dança e instrumentos. Utilizamos Reis (2007) para nortear os trabalhos com o grupo e aprofundarmos o conteúdo. Os instrumentos pandeiro e caxixi já faziam parte da rotina, sendo necessária a aquisição de um Berimbau. O atabaque foi substituído pelo Tambor (Rebolo). A professora Ana Gláucia havia identificado que o conteúdo capoeira faz parte da cultura capixaba, resultado do processo histórico de formação da sociedade espírito-santense.

Antes de iniciarmos esse tema, como o projeto de sala contemplava a cultura do município de Domingos Martins, a professora regente planejou trabalhar com uma dança típica da região: a Tarantella Napolitana. Desejamos apresentar esses dois trabalhos na festa cultural no dia 06/08. Considerando o perfil da turma e a resistência dos meninos em aceitar a dança, tentamos priorizar a capoeira para os meninos e a Tarantela para as meninas. Essa situação de gênero nos incomodava e ficamos refletindo sobre o que fazer, conforme registro de planejamento/avaliação: Como o projeto envolve música e seus elementos constituintes, decidimos trabalhar esse conteúdo (capoeira) no projeto com vistas à apresentação cultural no dia 08/06. A capoeira está sendo pensada para os meninos, todavia, o projeto acontecerá com todos da sala, respeitando as divisões por grupos às $5^{a}$ feiras. Paralelo a isso, a professora planejou trabalhar com a dança italiana "Tarantella Napolitana". A princípio, havia planejado trabalhar apenas com as meninas. Desta forma, os meninos ficariam com a capoeira e as meninas com a dança. Ficamos de decidir isso mais adiante, tendo em vista a possibilidade de todos participarem das duas apresentações.

Diante disso, seguimos com o planejamento das aulas de musicalização. A $10^{a}$ aula teve como tema a capoeira. A sequência didática contemplou 06 momentos:

1- Ouvir uma música de capoeira (Faixa 7, Cd “Cordão de Ouro”);

2- Apresentar os instrumentos;

3- Ensinar a história

4- Brincar com o fundamento "ginga" (Faixa 4 e 15, Cd "Cordão de Ouro”);

5- Apresentar alguns golpes; 
6- Jogar capoeira.

Seguimos com esse roteiro, com execução da roda e o jogo. Os instrumentos apresentados foram o berimbau, o caxixi, o pandeiro e o tambor. Os golpes foram vivenciados pelas crianças, com destaque para "meia-lua, cocorinha, estrelinha, queixada e a ginga", esta última como fundamento e execução dos golpes. Avaliamos que seria necessário aprofundar os movimentos. Para minimizar riscos, utilizamos tatames. Estes serviram de referência para os movimentos e posicionamento das crianças. A história da capoeira e dos instrumentos foi apresentada às crianças, contudo, a professora já havia conversado sobre o assunto em sala de aula. Elas já traziam as informações na ponta da língua. Pedimos a ajuda de um acadêmico de Educação Física da UFES para nos auxiliar, tendo em vista sua experiência com a capoeira e, também, por estar fazendo uma pesquisa de monografia no CMEI naquele período.

Os ensaios com a dança italiana aconteceram paralelos e dialogávamos buscando envolver a todos. Quando a professora levou as crianças para o laboratório de informática e apresentou a dança, houve o desejo de participação dos meninos. Eles viram que havia uma história e a "necessidade" dos homens compondo a apresentação. Decidimos focar os ensaios apenas nesse conteúdo, uma vez que se aproximava a Festa Cultural e os elementos da capoeira exigiam aprofundamentos que não daríamos conta a tempo. A experiência com a dança foi trabalhosa, mas gratificante.

Seguimos com os trabalhos com a capoeira até o dia 27/06. Foram mais quatro aulas, intercaladas com os ensaios e uma experiência com a culinária capixaba. No dia 27/06 a professora, em parceria com as pedagogas e cozinheiras do CMEI, fizeram uma "Moqueca Capixaba" na panela de barro. Essa experiência foi a culminância de uma sequência didática envolvendo visitas externas: passeios nas Paneleiras de Goiabeiras; na vila de pescadores da Praia do Suá; e passeio no Mercado Municipal da Vila Rubim, com suas peixarias e artesanatos ${ }^{14}$.

Esse atravessamento é típico da educação infantil e dialoga continuamente ao longo do ano. Retornando à capoeira, seguimos com novas aulas para desenvolver a ginga e agregar novos movimentos. Trabalhamos "o movimento da Arraia" e fizemos analogias a outros animais para facilitar a apropriação pelas crianças. Utilizamos os movimentos do caranguejo para associar à "cocorinha", o jacaré para os golpes com os pés. Em outra aula, trabalhamos no colchão. Fizemos vários movimentos: "bananeira, bananeirinha, estrelinha e aú". As crianças ficaram empolgadas com os movimentos e o uso do colchão facilitou a "liberdade da experimentação". Usamos a parede como apoio, apresentamos os exemplos dos colegas que conseguiam executar. O “aú”, outro movimento

14 Localidades dentro da região metropolitana de Vitória. A Moqueca Capixaba é um prato típico do Espírito Santo e leva peixe (foi utilizado o Cação), tempero verde, azeite, cheiro verde, tomate, cebola, alho, limão e sal (com variações) feito na panela de barro, herança cultural que permanece até a atualidade. 
da capoeira, foi executado pensando o "movimento do gato" quando dorme: ele roda até lançar as pernas para o ar, num movimento circular e fizemos uma aproximação com a estrelinha. Havia interesse das crianças, mas percebíamos que já estávamos nos distanciando dos objetivos do projeto. Encerramos esse trabalho com uma grande roda de capoeira, com uso dos instrumentos. As crianças tocaram e jogaram, com exploração das músicas "marinheiro só, peixe vivo, alface já nasceu, sapo na beira do rio". Juntar todos os elementos trabalhados em apenas um horário exigiu adequação do espaço.

O segundo semestre foi marcado pela exploração de músicas que possibilitassem o canto/a voz. Decidimos fazer uma seleção e apresentar às crianças para que escolhessem as que tivessem maior afinidade. Tentamos fugir das músicas do momento e oferecer novas possibilidades. Utilizamos os trabalhos dos Grupos Moxuara, Palavra Cantada, MPB 4, Bebossa Kids, Adriana Partimpim III, Raça Negra, Casaca, Toquinho. Foram 23 músicas para ouvir em sala de aula e deixar que as crianças se familiarizassem. Também deixamos o rádio ligado em momentos de Educação Física no pátio para estimular e aguçar as crianças. A partir do gosto delas fizemos uma nova seleção; a intenção era intercalar momento de canto, acompanhamento com os instrumentos e brincadeiras cantadas. As músicas escolhidas foram: Ainda amo você - Raça Negra; Alegria da vida, O Vira e A primeira estrela - Bebossa Kids; Marina - Banda Casaca. Ao longo dos trabalhos, as crianças apresentaram desenvoltura e acrescentaram outra música: Vagalume - Polo.

Os trabalhos seguiram ao longo do semestre e os encerramos no final de outubro, com a apresentação das crianças. Avaliação do projeto musicalização foi positiva, pois a oferta sistemática desse conteúdo demonstrou que as crianças aprendem, e mais, já possuem uma cultura musical que trazem de casa. Há necessidade de novos aprofundamentos e continuidade desse processo educacional ao longo da vida estudantil das crianças.

No final de 2013 fizemos uma avaliação do trabalho e consideramos alguns pontos centrais: os objetivos desejados foram trabalhados ao longo do ano e as crianças conseguiram alcançar um aprendizado significativo. Os elementos da música foram desenvolvidos. A falta de formação em música dificultou a atuação dos professores, uma vez que caminhávamos tateando as possibilidades. As crianças foram resistentes no início por associar esse momento com as aulas de Educação Física e a liberdade que possuem nos espaços utilizados, mas aos poucos foram reconhecendo as intenções do projeto. Sempre tentamos oferecer os conteúdos com uma abordagem lúdica e deixar que se apropriassem dos conhecimentos do campo da música. 
O trabalho desenvolvido no primeiro semestre de 2013 contemplou oportunizar às crianças a vivência de algumas práticas corporais, o acesso às culturas infantis, a estimulação das diferentes linguagens (oral, corporal, estética, expressão, musical e outras), experiências de estimulação dos sentidos, brincadeiras e diferentes práticas corporais - a partir da cultura corporal - pautados numa perspectiva lúdica.

Fizemos um planejamento a partir de "Temas Geradores", que consistiu em trabalhar um tema ou conteúdo por semana, permitindo-se vivenciar diferentes práticas nos espaços do CMEI (pátio, sala de movimento, “campinho”, salas de aula, corredores e "parquinho”). Esse trabalho foi em parceria com as professoras Suely e Nair, pois utilizamos dos mesmos materiais e espaços, além de trabalharmos com todas as turmas.

Entendemos que este trabalho é somativo, ou seja, as crianças têm oportunidade de trabalhar com diferentes materiais, viver situações de aprendizagens e troca de experiências na presença da professora regente (professora de sala), com os colegas de turma, com a professora de Artes (vivências desenvolvidas na sala de artes) e nas experiências culturais de movimento oferecidas pelos professores de Educação Física.

Nosso planejamento foi dividido por faixa etária. As crianças de 06 meses a 03 anos foram contempladas com brincadeiras, desafios, músicas infantis e populares - utilizamos o violão e alguns instrumentos de percussão, bolas de soprar, movimentos de ginástica geral - rolamentos, cambalhotas, trave de equilíbrio, mini-tramp, balanço, piscina de bolinha, manipulação de objetos variados, dança, trabalho com tecidos diversos, pneus e brinquedos de pátio. Os pneus foram materiais utilizados com todas as turmas: possibilitaram a construção de brincadeiras, desafios, imaginação, exploração livre, circuitos; fizemos pontes, "amarelinha", trilhas, esconde-esconde, corridas, rola-rola, arremesso, saltos e outras formas criativas que as crianças demonstraram ao utilizar tais objetos. Ainda tivemos a oportunidade de brincar de boxe, slackline - fita de equilíbrio, trapézio, argolas.

As crianças de 04 a 05 (completam 06 ao longo do ano) vivenciaram práticas culturais de movimento a partir dos esportes - futebol, basquete, voleibol, peteca - numa perspectiva lúdica, ou seja, um convite às brincadeiras e desafios; um trabalho com tecidos, com estimulação das linguagens e sentidos - fizemos túnel e pontes com tecido tubular, nos quais as crianças usaram a imaginação e experimentaram diferentes movimentos corporais, sensações de equilíbrio e desequilíbrio, queda, giro, recheados de fantasia, música e histórias; tecido elástico que permitiu o "voo", a "queda livre", tecido duplo que possibilitou movimentos de giro, sustentação, postura estática. A ginástica geral foi 
outro conteúdo explorado pelas crianças: os colchões possibilitaram os saltos, as piruetas, as cambalhotas, as posições estáticas. O mini-tramp (cama elástica individual para ginástica), além de oportunizar os saltos (uso comum), permitiu explorar o "salto mortal" (giro no ar) utilizando-se dos colchões e tecido elástico. Os balanços com cordas e pneus foram oferecidos às crianças ao longo do semestre, trabalhando-se o respeito ao colega, o esperar a vez, o compartilhar, a atenção, conteúdos de matemática. Os pneus foram materiais utilizados com todas as turmas: possibilitaram a construção de brincadeiras, desafios, imaginação, exploração livre, circuitos; fizemos pontes, "amarelinha", trilhas, esconde-esconde, corridas, rola-rola, arremesso, saltos e outras formas criativas que as crianças demonstraram ao utilizar tais objetos. Ainda tivemos a oportunidade de brincar de boxe, slackline - fita de equilíbrio, trapézio, argolas.

Nas aulas de Artes, a professora desenvolveu atividades de educação artística, com manipulação de objetos, colagens, desenhos coletivos, contação de histórias e brincadeiras infantis. A pintura com tinta guache, com uso de pincel, pinturas com o uso dos dedos, o trabalho com massa de modelar, utilização de cola colorida e a confecção de brinquedos/animais também foram oferecidos às crianças.

O trabalho com os conteúdos de arte foram desenvolvidos na "Sala de Artes", onde as crianças foram convidadas a ouvir histórias, fazer "releituras" desses contos infantis e brincar com a fantasia. A professora Nair abordou assuntos ligados às culturas infantis e possibilitou vivências com colagem, desenho livre, trabalho com massinha, pinturas de animais e objetos a partir das histórias. Utilizaram-se diferentes materiais recicláveis para confecção de brinquedos e atividades de artes. Foi possível, ainda, trabalhar algumas datas festivas, tais como o Carnaval, a Páscoa, o Dia das Mães e a festa cultural. Esses temas foram abordados com as crianças a partir de uma perspectiva formativa, evitando-se os aspectos religiosos. A "Sexta Alegre", que antecede o carnaval, foi marcada por danças, adereços e brincadeiras que remetem a uma grande diversão; no período da páscoa evitamos o apelo comercial do chocolate e trabalhamos a partilha. Para esta ocasião, profissionais da instituição, as crianças e suas famílias são convidados a arrecadar mantimentos e doar a uma instituição de caridade de Vitória.

Avaliamos que as crianças conseguiram vivenciar diferentes movimentos, tiveram acesso a variadas culturas de movimento, brincaram com vários objetos, manusearam diferentes tipos de artefatos, com formas e cores variadas, pesos e medidas diversos, cheiros e texturas diversificadas. Percebemos a alegria estampada em seus rostos, as tristezas quando comunicávamos o encerramento das aulas e a necessidade de retornar à sala de aula. Reconhecemos que as crianças foram protagonistas das práticas vividas nas aulas de Educação Física, sujeitos praticantes do cotidiano e inventores de culturas. 
As crianças dos Grupos IV, V e VI demandam um trabalho mais articulado e contamos com o apoio das estagiárias. Tendo em vista a atenção das crianças nessa faixa etária ser um desafio aos professores, procuramos dinamizar as aulas para permitir a apropriação dos conhecimentos, a alegria da descoberta, o prazer pela leitura e os primeiros ensaios textuais. O desenvolvimento da oralidade também é possibilitado nas aulas de Educação Física e Artes. As questões comportamentais também ocupam uma parcela da atenção dos educadores e as crianças nesta faixa etária estão aprendendo a compartilhar brinquedos, espaços e a companhia dos colegas. Estar em ambientes diferentes e sob a orientação de profissionais com formação específica significa, dentre outras possibilidades, conhecer o mundo e se apropriar da cultura.

O trabalho desenvolvido no $2^{\circ}$ semestre de 2013 ampliou as possibilidades de construção de conhecimento com as crianças, a partir do projeto "Brincadeiras Tradicionais". Oportunizou às crianças a vivência de algumas práticas corporais, o acesso às culturas infantis, a estimulação das diferentes linguagens (oral, corporal, estética, expressão, musical e outras), experiências de estimulação dos sentidos, brincadeiras e diferentes práticas corporais - a partir da cultura corporal pautados numa perspectiva lúdica.

Demos continuidade ao planejamento a partir de "Temas Geradores", que consistiu em trabalhar um tema ou conteúdo por semana, permitindo vivenciar diferentes práticas nos espaços do CMEI (pátio, sala de movimento, "campinho", salas de aula, corredores e "parquinho"). Entendemos que este trabalho almejou o desenvolvimento integral das crianças, ou seja, as crianças tiveram a oportunidade de trabalhar com diferentes materiais, viver situações de aprendizagens e troca de experiências na presença da professora regente, com os colegas de turma, com a professora de Artes (vivências desenvolvidas na sala de artes) e nas experiências culturais de movimento oferecidas pelos professores de Educação Física, reconhecendo esses sujeitos como protagonistas, sujeitos culturais e históricos, produtores de sentidos (culturas).

No segundo semestre demos encaminhamento às brincadeiras tradicionais, oferecendo a oportunidade das crianças brincarem de corda: pular corda, chicotinho queimado, cobrinha, passagem em níveis, falsa baiana; amarelinha, bolas de meia, bambolê, bolinha de sabão, peteca, ioiô, vai e vem, bilboquê e, também, brincamos de futebol, basquete. Em outubro buscamos desenvolver atividades recreativas, pois comemoramos o mês das crianças. Neste sentido, foram momentos com pula-pula, dança das cadeiras, gincanas, brincadeiras com bola de soprar e muita música. Em novembro revisitamos algumas práticas desenvolvidas ao longo de 2013 e oferecemos o slackline, os balanços, os mini-tramp's e algumas atividades com os tecidos, argolas e trapézio. Avaliamos que as crianças desejavam esse movimento de (re)viver essas experiências e demonstraram segurança na execução das atividades/vivências, já com apropriação do conhecimento e organização para 
aproveitar ao máximo as aulas. O último mês do ano foi marcado por banho de mangueira e piscina, tendo em vista o forte calor na cidade.

Nas aulas de Artes, a professora continuou a desenvolver atividades de educação artística, com manipulação de objetos, colagens, desenhos coletivos, contação de histórias e brincadeiras infantis, pintura com tinta guache, com uso de pincel, trabalhos com massa de modelar e, principalmente, confecção dos brinquedos vai e vem, bilboquê e outros jogos individuais com sucata/material reciclável.

Avaliamos que as crianças conseguiram vivenciar diferentes movimentos, tiveram acesso a variadas culturas de movimento, brincaram com vários objetos, manusearam diferentes tipos de artefatos, com formas e cores variadas, pesos e medidas diversos, cheiros e texturas diversificadas. Percebemos a alegria estampada em seus rostos, a aprendizagem que conseguiam demonstrar ao se organizarem para viver as práticas corporais trabalhadas ao longo de 2013; identificamos a apropriação das regras necessárias para que todos brincassem e aproveitassem o tempo das aulas. A oralidade foi estimulada a todo o momento, bem como elementos da matemática e acesso às culturas infantis.

O trabalho sempre ocorreu em parceria com as Assistentes de Educação Infantil, com as Estagiárias e o olhar das Pedagogas. Reforçamos a necessidade desses profissionais no acompanhamento das turmas, tendo em vista as possibilidades de intervenções e a ampliação das práticas docentes. Permite "liberdade" para ousarmos oferecer novos desafios e explorar diferentes possibilidades com as crianças. O cuidado e a atenção são "redobrados" com a presença desses profissionais, permite-se, ainda, uma interação com as crianças e a criação de novos conhecimentos e novas culturas infantis.

Os tempos de planejamentos individuais e coletivos foram fundamentais para oferecermos uma educação infantil de qualidade. Permitiram avaliarmos o processo e acompanharmos o caminhar das aulas. Atentamos para as particularidades que cada turma apresentava, bem com estávamos atentos às necessidades que cada faixa etária exige. Acreditamos ter oferecido experiências e vivências significativas às crianças da Educação Infantil.

Em 2013 buscamos dialogar com os trabalhos de sala, por considerar a integralidade do currículo da educação infantil. Foi possível trabalharmos com música, instrumentos de percussão, passeios externos, atividades de gincana, apresentações culturais. Fizemos os registros e disponibilizamos o material no site you tube mediante autorização dos pais, conforme arquivo do CMEI. A divulgação objetiva oferecer o acesso a algumas vivências das crianças e oportunizar aos pais o acompanhamento da dinâmica na instituição. Para além, desejamos compartilhar as práticas com outras instituições de educação infantil, acreditando que estamos atendendo às demandas 
formativas propostas nas diretrizes curriculares nacionais, bem como reconhecendo o direito das crianças a uma educação infantil de qualidade.

O ano se encerrou com a certeza de produção de conhecimento e aprendizagem das crianças. Em momentos de aulas de Artes as crianças utilizaram os pinceis, fizeram colagem, brincaram com diferentes objetos e materiais pedagógicos. A escrita e leitura aconteceram em diferentes espaços do CMEI, sendo respeitados os tempos das crianças e as particularidades de cada grupo etário. As experiências de movimento e o acesso à cultura também marcaram esses momentos de formação humana. As crianças aprenderam a conviver e respeitar os colegas e professores; conseguiram se expressar verbalmente e manifestar suas alegrias e frustrações. Entendemos que foram oferecidos diferentes momentos formativos e, para além, reconhecemos as crianças nas suas ações, nos seus direitos de aprender e estar na educação infantil; cidadãos de pouca idade que nos ensinaram a valorizar a vida, a não guardar inimizades, a acreditar que o hoje pode ser cada vez melhor. Entendemos que a educação infantil possui particularidades, especificidades e, como professores, precisamos nos atualizar a cada dia.

\section{Considerações Finais}

A coletividade, expressa nas práticas analisadas neste trabalho, permite evidenciar as especificidades desse espaço educativo. Os interesses dos sujeitos caminham no sentido do atendimento das necessidades das crianças que incluem os aspectos do cuidar e educar.

As especificidades das áreas de conhecimento também compõem esse universo formativo. Consideramos importante a diferente formação dos professores e a ampliação das possibilidades de acesso aos conhecimentos e culturas infantis. Ter oportunidades de vivenciar e experimentar conteúdos e metodologias específicas de Artes, Educação Física e Música pode significar tanto a consolidação de bases futuras, quanto o atendimento das especificidades das crianças hoje.

As crianças são reconhecidas como protagonistas da ação e sujeitos desejantes e merecedores da atenção dos adultos. A convivência nas instituições infantis possibilita ampliarmos os saberes e experiências que atravessam cada pessoa, compõem as subjetividades e demonstram as capacidades criativas e inventivas das crianças. Ao longo do ano elas foram capazes de mostrar que a vida sempre se reinventa, que na escola também é lugar de se divertir e aprender. Elas foram (são) capazes de se expressar por diferentes linguagens, demonstraram que aprenderam se divertindo, criaram estratégias de estar no CMEI e ser felizes. Os desejos que nos moveram ao encontro das crianças confirmam a satisfação de trabalhar para um presente melhor.

Os planejamentos individuais e coletivos carecem de novas articulações. O que observamos 
foram desejos pontuais e articulações possíveis. A participação das pedagogas nas práticas docentes, espaços, rotinas e famílias demandam uma formação inicial que atente às especificidades da educação infantil. Exige-se formação continuada para acompanhar as mudanças nos conceitos e concepções de infância e criança que estão em constante diálogo com as mudanças sociais de cada geração, numa velocidade cada vez mais acentuada que nos parece encurtar as infâncias ou alongá-las para alguns.

Sentimo-nos desafiados a planejar coletivamente, rompendo com as práticas individualizadas e restritas a apenas o ambiente de sala de aula. Desejamos um fazer coletivo que inclua as crianças como sujeitos praticantes, como nos propõe Certeau (1994). O desafio que nos acompanha a cada ano é oferecermos uma educação infantil que seja significativa para o sujeito criança nesse tempo presente, no reconhecimento das especificidades da infância que brinca e aprende. 
Referências

ACEAV. Ensino da música. 2008/2009. Disponível em: eb23abarb.prof2000.pt/escola/...09/.../EMusica/Planif_E_Musica_1P.pdf . Acesso em: $22 / 02 / 2013$.

BRASIL. Ministério da Educação e do Desporto. Referencial Curricular Nacional para a Educação Infantil. Brasília: MEC/SEF, 1998. v. 3.

CRAIDY, Carmem Maria; KAERCHER, Gládis Elise P. da Silva (Orgs.). Educação infantil: pra que te quero? Porto Alegre: Artes Médicas, 2001.

CERTEAU, M. A invenção do cotidiano 1: as artes de fazer. Petrópolis: Vozes, 1994.

COLÉGIO PEDRO II. Apostila de educação musical. Portal de Educação Musical do Colégio Pedro II. Disponível em: http://www.portaledumusicalcp2.mus.br/. Acesso em: 22/02/2013.

REIS, André L. T. Brincando de capoeira: recreação e lazer na escola. Brasília: Ed. Valcy, 1997. 